\title{
FORMAÇÃO DA CLASSE TRABALHADORA NA ARGENTINA
}

Cristina Campolina*

cristinacampolina@hotmail.com

RESUMO: Esse artigo trata da formação da classe trabalhadora argentina, a partir da influência dos imigrantes europeus que entraram no país, na segunda metade do século XIX. As ideologias de esquerda já conhecidas na Europa, e trazidas pelos imigrantes serão fundamentais na organização da classe operária e na formação do sindicalismo argentino.

Palavras-chave: Argentina, classe trabalhadora, sindicatos

ABSTRACT: This article deals with the formation of the Argentine working class, as from the influence of European immigrants who entered the country in the second half of the nineteenth century. The ideologies of the Left Wing, already known in Europe and brought by the immigrants, are fundamental for the organization of the working class and the formation of Argentine unionism.

Key words: Argentina, working class, unions

O processo histórico de formação da classe trabalhadora como ator político na Argentina é fator importante para a análise da história econômica, política e cultural do país. Essa classe formada no século XIX cumpriu um papel fundamental no cenário político, principalmente durante

* Doutora em História pela UFMG; professora adjunta do Departamento de História da UFMG. Este artigo é parte da tese de doutorado defendida em novembro de 2007, sob a orientação da Profa. Dra. Heloísa Maria Murgel Starling. 
o processo de ascensão de Juan Domingo Perón à presidência da República em 1946.

A partir da segunda metade do século XIX, começou o processo de diversificação na estrutura produtiva do país provocado principalmente pela grande exportação de lã. À época, com o crescimento das cidadesporto, aumentou vertiginosamente a demanda de mão- de-obra, sobretudo a qualificada. Assistiram-se, então, a dois movimentos de população diferenciados: as imigrações européias e as migrações internas. ${ }^{1}$ O fluxo maciço de estrangeiros para o país, principalmente a partir de 1880, foi responsável por mudanças sociais, culturais e econômicas no período conhecido como "the alluvial era". ${ }^{2}$ As migrações internas se deram, sobretudo, depois da Grande Depressão, com o crescimento do setor industrial no país.

Quanto à distribuição da população argentina entre as áreas urbanas e rurais, tem se que, em 1869, mais da metade da população estava nas zonas rurais. Em 1895, a desproporção entre as duas áreas foi estreitada e, já 1914, a maioria da população estava nos grandes centros urbanos. Em 1947, 62,5\% da população morava nas cidades. Para essa característica contribuíram o êxodo rural e imigração de estrangeiros, desde o fim do século $\mathrm{XIX} .^{3}$

A grande maioria dos imigrantes que chegou à Argentina estabeleceu-se nas grandes cidades. O primeiro censo em 1869 mostrou que 87\% dos estrangeiros estavam radicados em Buenos Aires, Santa Fé e Entre Rios. Havia imigrantes de quase todas as nações da Europa, África e Ásia, mas foram os três países mediterrâneos - Itália, Espanha e França - e os limítrofes da Argentina - Chile, Brasil, Paraguai e Bolívia que contribuíram com a maior parte deles, cerca de $85 \%$ do total. A proporção de migrantes internos sobre o total da população era de $8,3 \%$, destacando-se Buenos Aires como unidade espacial separada, essa proporção elevava-se a $14,4 \%$. Tanto migrantes como os imigrantes não constituíam grupos homogêneos entre si. Pelo contrário, 
eram altamente diferenciados formando subgrupos de acordo com sua região de origem (LATTES, 1972, p. 15-27). ${ }^{4}$

De acordo com Germani (1970, p. 303), até o final do século XIX, a composição social do país estava formada por duas classes, não existindo entre elas, uma classe numérica e economicamente forte. A estrutura político-econômica vigente dificultou a conversão do imigrante em dono de terra. O Estado foi ineficiente em facilitar a aquisição de maquinário agrícola, que estimularia a fixação dos imigrantes nas áreas rurais. Por outro lado, a população imigrante já tinha entrado no país com a intenção de mudar de vida e abandonar a ocupação, predominantemente rural, que tinha em seu país de origem. A combinação desses dois fatores foi decisiva para promover um distanciamento dos imigrantes do campo e sua concentração nas cidades, principalmente em Buenos Aires, com ocupação gradativamente maior nos setores secundários e terciários da economia.

O segundo censo argentino realizado no ano de 1895 detectou grandes transformações nos 26 anos intercensais. Houve imigração maciça, ampliação da agricultura e uma significativa transformação do setor pecuário. Numa estimativa aproximada, cerca de 400.000 trabalhadores ocupavam-se da produção de matérias-primas (agricultura e pecuária) sendo 250.000 argentinos e 150.000 estrangeiros. Os primeiros dedicaram-se principalmente à pecuária, enquanto os segundos alocaram-se nas regiões dedicadas à agricultura.

Entre 1914 e 1946, a entrada de imigrantes na Argentina diminuiu bastante com a mudança de orientação da política imigratória. Somou-se a isso a condição externa pouco propícia à imigração com a Primeira Guerra Mundial e a crise econômica de 1929. À exceção dos anos 1921 e 1930, os saldos imigratórios diminuíram significativamente, aumentando a partir de 1947 pela nova demanda de mão-de-obra interna e pelo contingente populacional europeu que se refugiou na América no pós-guerra. 
As províncias que absorveram a maior quantidade de estrangeiros foram: Buenos Aires, 305 estrangeiros para cada 1.000 habitantes; Santa Fé, 156 para cada 1.000 habitantes; Entre-Rios, 136 para cada 1.000 habitantes; Corrientes, 68 para cada 1.000 habitantes. A concentração da população, principalmente, na Capital Federal e seus arredores foi uma característica demográfica do país, evidenciada no censo de 1914. Este também revelou que $49 \%$ do total da população da Grande Buenos Aires era estrangeira.

Segundo Beyhant (DI TELLA et al. apud, 1965), entre 1914 e 1935 houve uma redução no processo de urbanização pelo declínio da imigração estrangeira; mas, a partir de 1936 as cidades receberam levas de migrantes internos, provenientes de centros urbanos menores e das zonas rurais.

No caso da Argentina, a intensificação das migrações internas coincidiu com as crises produzidas pela evolução desfavorável dos termos de intercâmbio internacional e a consequente diminuição da capacidade importadora do país. Essa favoreceu o rápido crescimento industrial, localizado sobretudo na Grande Buenos Aires, caracterizado pela substituição de importação de bens de consumo. Nesse ambiente de mudanças econômicas e sociais deram-se a incorporação definitiva da Argentina na economia mundial, e a formação da classe operária do país.

Essa corrente migratória começou a ganhar força quando o fluxo de imigração começou a decrescer. Desde o início da década de1930, em função da política protecionista e da industrialização, já se percebia nas cidades o fluxo migratório proveniente, principalmente, daquelas áreas não afetadas pela imigração estrangeira até os centros urbanos já transformados pelo impacto imigratório. A população da Grande Buenos Aires, por exemplo, cresceu entre 1934 e 1943 em um ritmo anual de 85.000 habitantes dos quais 72.000 eram provenientes do interior, entre 1943 e 1947, esses números elevaram-se em 117.000 habitantes por ano. Nota-se que a 
distribuição espacial dessa população migrante se concentrou, assim como os estrangeiros, em Buenos Aires, Santa Fé e Entre Rios.

Segundo Germani (1965, p. 226), essa grande massa de peões rurais, artesãos ou "personal de fatiga", transplantada de maneira rápida às cidades e transformada em operários industriais, adquiriu significação política sem que ao mesmo tempo tivesse acesso aos canais institucionais necessários para integrar-se ao funcionamento da democracia. A política repressiva dos governos desde os fins do século XIX até começos do século $X X$, a ambivalência e relativo fracasso dos governos da classe média entre 1916 e 1930, as severas limitações ao funcionamento da democracia depois desta data, a descrença e o ceticismo unidos à ausência de partidos políticos capazes de proporcionar uma expressão adequada a seus sentimentos e necessidades, deixaram essas massas disponíveis para serem aproveitadas por qualquer aventureiro que lhes oferecesse alguma forma de participação, em clara referência a Perón.

\section{ORGANIZAÇÃO DA CLASSE TRABALHADORA}

Os primeiros esforços para organizar a classe operária na Argentina não foram uma iniciativa de uma classe eminentemente criolla. Bailly (1984, p. 20) aponta a forte influência estrangeira desde meados do século XIX, nos primórdios da formação da classe operária argentina. Segundo o autor, os estrangeiros trouxeram seus métodos de organização e agitação assim como programas e ideologias. Entre 1857 e 1910, o número de estrangeiros era superior nas organizações operárias e na liderança. Em comparação com o imigrante, os nativos não estavam organizados para questionar a ordem social e econômica vigente, mas também não se opuseram aos imigrantes quando esses organizaram e conduziram o movimento operário. 
Entende-se que as possibilidades de vitória dos trabalhadores de uma jovem nação, que no seu período pós-independência foi cenário de sangrentas lutas internas, governada por caudilhos e sem nenhuma prática no exercício da cidadania, seriam poucas. A experiência histórica dos trabalhadores argentinos, em grande parte indígenas, dificultaria as suas possibilidades de participação política, pelo menos através dos canais institucionais tradicionais. No entanto, em que pese os limites inerentes à imensa massa de trabalhadores, analfabetos e tiranizados por governantes que na maioria dos casos, não eram legítimos representantes do povo - aderir ao movimento organizado por estrangeiros não lhes extraiu o protagonismo.

De acordo com Macpherson (1978, p. 91), a Argentina viveu esse processo e não escapou do temor liberal relativo às consequências "perversas" que poderiam advir dos institutos da soberania popular e da igualdade política - cada cabeça um voto e todos os votos com o mesmo valor. No entanto, a "tirania da maioria", que era a consequência esperada em função da extensão da cidadania política a todos os indivíduos alfabetizados maiores de 18 anos não se deu, porque essa não foi acompanhada da universalização do direito de vocalização das preferências. Os novos cidadãos tinham apenas o direito de escolher entre os candidatos apresentados, ou seja, as alternativas dadas não foram formuladas por eles.

As correntes ideológicas que tiveram ressonância no meio operário argentino entre, 1870 e aproximadamente 1914, foram o anarquismo, o socialismo e o sindicalismo. 0 comunismo só apareceu depois de 1918, quando foi fundado no país o Partido Socialista Internacional, denominado Partido Comunista em dezembro de 1920.

Por volta de 1870, o anarquismo foi introduzido na Argentina e difundiu-se principalmente entre os operários que pertenciam às sociedades de resistência formadas nas últimas décadas do século XIX. ${ }^{5}$ Sua difusão deveuse à propaganda que faziam destacados anarquistas europeus como Enrico 
Malatesta e Pietro Gori que estiveram no país durante 1885-89 e 1898-1902, respectivamente (DEL CAMPO, 1971, p. 44). Ainda que houvesse diversas tendências dentro do anarquismo, mesmo entre Malatesta e Gori, no final do século XIX as quatro características fundamentais que prevaleceram na Argentina até a primeira década do século XX foram: a ação coletiva, a greve contra o Estado, o apoliticismo e o internacionalismo (MATSUSHITA, 1983, p. 24). $O$ anarquismo defendia a ação coletiva direta: os operários deveriam organizar-se em sindicatos para combater com êxito a classe capitalista. Por essa razão os anarquistas se empenharam muito na organização de sindicatos, enquadrando o anarquismo de então no anarco-sindicalismo. A greve era o método de luta entendido pelos anarquistas como a arma mais eficaz para destruir o Estado. $O$ antipoliticismo se expressava na oposição à formação de partidos políticos que, segundo os princípios do anarquismo, acabava por incorrer na busca do poder político, daí ser a organização de cunho puramente econômico. Defendiam também o internacionalismo: a pátria era o mundo inteiro, as fronteiras entre os povos não tinha razão de ser. $^{6}$

Notadamente, a história do movimento trabalhista argentino até aproximadamente 1910 foi fortemente marcada pela influência dos anarquistas. Com base nas teorias que já prevaleciam na Europa a ideia angular do anarquismo seria a destruição do Estado nacional para reconstruir uma sociedade "pura" e regenerada. A consequência gerada por esse tipo de ação foi a repressão duramente imposta pelo Estado ao ativismo insurrecionalista dos anarquistas na primeira década do século XX. Era impossível ameaçar continuamente a ordem estabelecida no país sem sentir o peso da reação dos aparelhos repressivos do Estado.

O socialismo foi outra ideologia que disputou o controle do movimento operário paralelamente aos anarquistas. Em 1882, foi formada na Argentina a primeira importante organização socialista por trabalhadores 
alemães refugiados de Bismarck. Era um grupo político parecido com o Vorwarts alemão (German Worker's Club), do qual conservou seu nome e inspiração. Seu semanário, chamado Vorwarts, apareceu com uma certa regularidade após a publicação de seu primeiro número em 1886. Com a intenção de repetir na Argentina o sucesso do Germany's Social Democrats, - Clube só obteve sucesso entre os imigrantes da comunidade germânica (ODDONE, 1949, p. 196-197).

Os socialistas passaram a ter influência no movimento operário depois da fundação do Partido Socialista Argentino (PSA) em 1896, sob a liderança do argentino Juan B. Justo. Em 1890, Justo, recém-chegado de uma temporada de dois anos na Europa, integrou o comitê executivo da União Cívica, para pouco tempo depois, desiludido com o Partido, entusiasmarse com as idéias socialistas. Em 1894, apareceu a primeira edição do jornal socialista La Vanguardia. Justo foi o seu primeiro editor.

Durante os primeiros anos do século XX, quando a sociedade argentina assistia à violência do círculo vicioso de ação e reação trabalhador/Estado -, o PS posicionava-se entre as medidas extremistas dos anarquistas e as táticas restritivas dos conservadores. Claramente defensores das demandas da classe trabalhadora, os socialistas não concordavam com políticas extremistas como a greve geral, por considerá-las contraproducentes e estimuladoras de medidas repressoras por parte do Estado. ${ }^{7}$ No entanto, mesmo não sendo o alvo específico da polícia, o Partido Socialista sofreu severas sanções, entre elas a suspensão da circulação do jornal La Vanguardia, que continuou a sair clandestinamente.

Sob a mira do Estado que, entre 1902 e 1910, foi implacável na repressão às manifestações públicas da classe operária, fossem essas moderadas ou extremistas, ${ }^{8}$ as tensões aumentavam entre os trabalhadores socialistas e anarquistas - impedindo a possibilidade de uma luta organizada que, a partir de uma linha mestra única, enfrentasse o Estado. 
O sindicalismo, outra corrente ideológica européia forte no movimento operário argentino, foi introduzido no país em 1903 por dissidentes socialistas. A essência da ideologia dos sindicalistas podia ser traduzida na seguinte frase: o sindicato e não o partido político é a principal arma da luta proletária. O sindicalismo apareceu como uma reação contra os partidos socialistas de tendência reformista e parlamentarista. Isso não significa que os sindicalistas não reconhecessem certo valor na atividade parlamentar, ou nos partidos que servissem aos interesses da classe. Eles se opunham ao antipoliticismo do anarquismo, mas também não confiavam irrestritamente no parlamento, assim como os socialistas. Os sindicalistas colocavam-se em uma posição intermediária entre as duas tendências: socialistas e anarquistas. Segundo o italiano Arturo Labriola, um dos ideólogos do sindicalismo, os sindicatos são as únicas instituições que respondem à mecânica interna da luta de classes. Labriola defendia a Confederação dos sindicatos como a forma natural da organização da classe operária e afirmava que: "Nela (a Confederação) se organiza precisamente a classe como tal: os proletários como tais" (LABRIOLA,1987, p. 198). [Tradução do autor.]

Em oposição ao socialismo freqüentemente rudimentar $e$ pobremente expresso desse período estava o movimento anarquista que sobreviveu até 1920. A magnitude da influência conseguida pelo movimento anarco-sindicalista argentino provocou fortes reações do governo para frear sua expansão.

Como instrumento legal para tal propósito, o Estado usou da Ley de Residencia (lei 4.144) sancionada em 1902 e a Ley de Defensa Social (lei 7.029) de 1910. Ao lado dessas, a Lei Eleitoral de 1912 eliminou sobremaneira a marginalidade dos operários nativos. ${ }^{9}$ Por essas razões a década de 1920 registrou um enfraquecimento do movimento anarquista pela expressiva diminuição de associados. 
Às vésperas do século $X X$ a Argentina tinha dois partidos políticos organizados, a Unión Cívica Radical (UCR) e o Partido Social Obrero Internacional que em 1896 passou a chamar Partido Socialista Argentino (PSA). A UCR tinha como principal objetivo a derrocada da oligarquia e defendia alguns pontos em comum com o PSA como o sufrágio universal, o sistema eleitoral proporcional e a autonomia municipal. Enquanto as questões políticas eram mais importantes para os radicais, os socialistas colocavam ênfase nos problemas sociais e econômicos. Justo sempre advogou pela assimilação do trabalhador imigrante por acreditar que esses seriam mais capazes de desenvolver o socialismo na Argentina. Segundo suas previsões, em pouco tempo os "velhos elementos criollos" seriam absorvidos pelos imigrantes que constituíam a parte ativa da população.

Mais avançados politicamente que os radicais, os socialistas propunham: sufrágio para mulheres, maior facilidade para a naturalização dos estrangeiros, medidas anti-clericais e a defesa do divórcio. A essas propostas os radicais se opunham assim como na questão do poder político. Os socialistas acreditavam que poderiam participar do admitidamente corrupto processo político do país e contribuir para modificações significativas na vida nacional, através de um modelo moderno de organização política. Para os radicais, a única forma possível de eliminar a corrupção seria uma política de total intransigência, afirma Richard (1977, p. 22).

Em 1906, os sindicalistas passaram a controlar a Unión General de Trabajadores (UGT), até então sob o comando dos anarquistas, e também a Confederación Obrera Regional Argentina (CORA) criada em 1909, da qual participavam alguns socialistas e anarquistas. Em 1914, a CORA uniu-se à Federación Obrera Regional Argentina (FORA), uma das mais importantes centrais operárias das primeiras décadas do século $X X$, dirigida por anarquistas. No IX Congresso da FORA realizado em 1915, a hegemonia sindicalista era evidente, segundo Matsushita (1983, p. 31). 
Enquanto o socialismo e o anarquismo sofriam violenta repressão por parte do Estado desde o início do século XX, o sindicalismo, por apresentar uma ação mais moderada, foi a tendência que mais se expandiu até a década de 1920. Ao lado disso, na medida em que os sindicatos mais ligados ao setor exportador - marítimos e ferroviários - começaram a ter mais importância, os operários se tornaram cada vez mais combativos e optaram pela via sindical na reivindicação de seus objetivos econômicos. "Nesse aspecto, a luta pela solidariedade entre todos os operários, na perspectiva anarquista, perdia sentido no ponto de vista dos setores mais qualificados da economia nacional" (ROCK, 1977, p. 101-102).

Matsushita (1983, p. 32) atribui o crescimento do sindicalismo no pós Primeira Grande Guerra à tímida política trabalhista do presidente radical HipólitoYrigoyen (1916-1922) e também à perda do conteúdo filosófico do sindicalismo. Em primeiro de abril de 1915, foi realizado em Buenos Aires o IX Congresso do FORA. Os congressistas encontravam-se divididos entre duas tendências: a sindicalista e a anarco-sindicalista. A proposição mais importante apresentada pela comissão designada para elaborar os fundamentos ideológicos do FORA foi a anulação da resolução do V Congresso que era favorável ao comunismo anárquico, substituindo-a por uma definição ideológica plural.

Segundo esta proposição vencedora pelo voto, deliberava-se que o FORA:

(...) é uma instituição eminentemente operária, organizada por grupos de ofícios afins, cujos componentes pertencem às mais variadas tendências ideológicas e doutrinárias, que para manterem-se em sólida conexão necessitam a mais ampla liberdade de pensamento, ainda que em suas ações seja imprescindível que se enquadrem dentro da maior orientação revolucionária da luta de classes, da ação direta e com absoluta independência dos grupos e partidos políticos que militam fora da organização dos trabalhadores argentinos. O FORA não se pronuncia partidário nem aconselha a adoção de sistemas filosóficos nem ideologias determinadas (...) deverá permitir o mais amplo e 
tolerante discurso de temas científicos, filosóficos e ideológicos, em homenagem aos diferentes modos de pensar dos trabalhadores federados (...). (MAROTTA, 1960-1961, p. 186 ${ }^{10}$ ). [Tradução do autor.]

Além disso, o IX Congresso indicou a hegemonia sindicalista e reafirmou as posições tradicionais do conjunto do movimento operário, como a redução da jornada de trabalho, contra leis repressivas, escolas livres, e em favor do livre-cambismo. Na resolução a favor do livre-cambismo houve uma coincidência entre sindicalistas, anarco-sindicalistas e a minoria socialista. Segundo esta resolução,

(...) considerando que tudo quanto seja imiscuir-se nos interesses unilaterais da classe burguesa ou em suas expressões materiais, que são a indústria e o comércio, cuja gestão direta lhes pertence, é contribuir para a confusão no critério proletário quanto às finalidades das duas classes que se excluem entre si e que medidas de proteção oficial à indústria têm uma marcada tendência particularista, que se patentizam em não ocupar-se com os prejuízos que impõem ao proletariado em geral, explicando-se este fato pela índole da classe dos governos burgueses que as ditam, resolve: pronunciar-se contra o protecionismo, pelo qual reconhece que se bem o intercâmbio livre e universal pode em certos casos levar interesses circunscritos, o protecionismo representa uma forma artificial de concorrência na produção que só pode sustentar-se às expensas das classes consumidoras encarecendo o preço real das mercadorias. (MAROTTA, 1960-1961, p. 187). [Tradução do autor.]

Foram posições políticas como essas que caracterizaram o sindicalismo. Se por um lado, não radicalizavam ideologicamente, por outro lado, tinham claros os limites impostos aos trabalhadores em razão das práticas políticas da burguesia.

A partir do IX FORA, ${ }^{11}$ a corrente sindicalista, como já foi mencionado, registrou uma expansão que se acentuou por toda a década de 1920. A história da ascensão do sindicalismo, como conseqüência de uma posição mais branda conforme decisão no IX Congresso, teve um significado muito expressivo na política operária em geral. Uma vez que não se enfrentava 
o governo diretamente e na busca de ganhos mais imediatos dos benefícios sociais, o melhor seria recuar ou pelo menos buscar estratégias de luta mais institucionais. ${ }^{12}$

Embora o novo movimento operário organizado tenha alcançado seu apogeu em 1920, a eleição de Marcello T. Alvear para a presidência da República, em 1922, indicou um retrocesso na política trabalhista do governo de Yrigoyen. O FORA IX foi dissolvido em 1922 e substituído pela Unión Sindical Argentina (USA.). Quando da dissolução do FORA, o PCA criado em 1920 , já se pronunciava abertamente sobre as questões operarias. ${ }^{13}$

Desde a formação do PCA em 1920, os comunistas que atuavam dentro do FORA desenvolveram uma árdua campanha a favor da unidade sindical. No X Congresso do FORA realizado entre 29 e 31 de dezembro de 1918, os comunistas organizaram o Comité de USA que, no Congresso de 1922, substituiu definitivamente o FORA. Na USA os comunistas mantiveram certa influência apoiando os sindicalistas, enquanto os grêmios ferroviários, controlados pelos socialistas, retiraram-se para formar em 1926, junto aos sindicalistas reformistas, a Confederación Obrera Argentina (COA), que contou com 80 mil cotizantes, dos quais 70 mil eram ferroviários: " $L a$ Fraternidad" e a "Unión Ferroviária". À diferença da liderança do FORA IX, os dirigentes da USA interpretaram o gremialismo apolítico de tal forma que eliminaram por completo sua colaboração com o governo. Eles acreditavam que o programa de seus predecessores (FORA IX) tinha sido infrutífero, pois não evitou o desemprego, e propiciou o enfraquecimento do movimento operário. A declaração dos princípios que norteavam a USA foi um intento de reativar programas contra o Estado, próprio dos anarquistas anteriores à Primeira Guerra Mundial. Sustentavam que:

só a ação direta, o incessante batalhar nos sindicatos, a educação revolucionária do proletariado, têm dado frutos positivos, livrando os trabalhadores de tutelas vergonhosas de políticos e espertalhões de toda espécie; (...) que as tendências proletárias argentinas são 
manifestamente adversas ao colaboracionismo, anti-políticas e ferventemente revolucionárias. (MAROTTA, 1960-1961, p. 83-84). [Tradução do autor.]

Ao lado da declaração de princípios, a USA determinava entre outras medidas, o direito de intervenção e tutela às facções organizadas em partidos políticos. Eles reafirmavam a luta contra o imperialismo, chegando ao extremo da revolução social, e finalmente conclamavam, 'todo o poder aos sindicatos', para o caso de uma efetiva revolução como a única que se enquadra à tradição sindical revolucionária do país.

Analisando o pensamento ideológico do USA, Del Campo (1983, p. 29) afirma que a Central calculou mal a natureza e a importância das mudanças ocorridas na classe operária. As divergências entre as diversas correntes ideológicas transformaram o primeiro congresso da USA, em abril de 1924, em um campo de batalha entre sindicalistas (maioria), comunistas e socialistas. Em 1926, os sindicalistas de orientação socialista sentindo-se rechaçados pelo "embandeiramento" sindicalista da USA e por seu extremismo verbal, decidiram formar a referida COA que, entre 1926 e 1930, foi a federação mais importante de todo o país.

Finalmente, às vésperas da Revolução de 1930, o movimento operário argentino estava dividido em quatro centrais: FORA, COA, USA e o Comité de Unidad Sindical Clasista (CUSC), central comunista criada em 1929 por dissidências com os princípios da USA. Matsushita (1983, p. 43-44) afirma que esta divisão não favoreceu os interesses da classe trabalhadora, que sofria o problema de desocupação sob a aparente prosperidade da década. Segundo o mesmo autor, quando em 1930, os integrantes do COA e do USA se uniram para formar a Confederación General del Trabajo (CGT), essa nascia com uma importância primordial no período que precedeu ao surgimento do peronismo. 


\section{CONCLUSÃO}

No caso da formação da classe trabalhadora argentina, foi de importância fundamental a articulação da cultura operária local com a cultura dos imigrantes de diferentes procedências e também com a cultura da elite. É necessário reconhecer que não existe um espaço delimitado na sociedade para esse ou aquele indivíduo ou classe social desenvolver suas idiossincrasias. Na medida em que os imigrantes chegavam à Argentina, instituía-se paulatinamente a combinação das culturas através da influência recíproca entre trabalhadores nativos e trabalhadores estrangeiros e numa perspectiva mais ampla com os outros setores da sociedade. ${ }^{14}$

Há de se considerar as características da história do capitalismo nos países periféricos em geral e as particularidades sócio-culturais de cada um deles. No caso argentino, a economia agro-exportadora articulava-se como parte do sistema capitalista mundial sem passar pela lenta formação das cidades; tampouco a industrialização atravessou o processo clássico, desde a cooperação capitalista simples até a constituição de um proletariado de origem servil. A classe operária formou-se com imigrantes provenientes de países capitalistas associados aos trabalhadores de um país de economia periférica, exatamente quando se dava o início da fusão do socialismo com o movimento operário em escala internacional. Isso significa que esses imigrantes já chegavam à Argentina predispostos a dar continuidade à luta social iniciada nos países de origem e nesse novo lugar, traduzi-la para outra língua e para outro contexto político, social e, sobretudo, intelectual (COSTA, 1985 , p. 17)..$^{15}$

Nesse sentido as aspirações frustradas desses imigrantes ao chegarem na Argentina refletiram-se na ação de resistência ao capital e na forte predisposição para assimilar ideologias anarquistas e socialistas que já conheciam. Os imigrantes tiveram que inteirar-se com os trabalhadores nativos, aceitando-os e também se integrando à cultura nacional dentro dos 
limites inerentes ao status de imigrante. O paradoxo da situação ficou patente na forma que esses estrangeiros atuaram na reivindicação de seus direitos, como trabalhadores e através da ação política, como aspirantes a cidadãos. A organização política foi a forma usada por esses trabalhadores para evitar a repetição das condições de exploração sofridas nos países de origem. Os movimentos sociais organizados com essa finalidade foram ordenados no interior da nova sociedade, então composta de uma grande quantidade de trabalhadores estrangeiros e argentinos.

A luta pela conquista da cidadania e dos direitos sociais e políticos iniciou-se no século XIX, mas a implantação pelo Estado de uma política trabalhista, conquistada pelos trabalhadores, coube ao final da primeira metade do século XX com a ascensão do peronismo.

NOTA:

(Endnotes)

1 Para migrantes usa-se o conceito de Alfredo Lattes (1972, 9): "São migrantes as pessoas que frente ao censo residem em um lugar distinto de seu nascimento" (para nativo-distintas províncias).

2 Desde a Independência em 1810, o novo regime esteve aberto à entrada de estrangeiros no país com o objetivo de eliminar o isolamento imposto pelos colonizadores. Ver sobre o tema Germani (1970, p. 289-331).

3 “Aportaciones Positivas de los Migrantes", Revista de la Dirección Nacional de Migrante (Republica Argentina, Ministerio del Interior, Ano I, n. I, enero-marzo, 1959, Unesco), p. 171.

4 A não-homogeneidade entre os imigrantes também foi ressaltada por Bourdé (1987) em vários aspectos: nível de instrução, nível de qualificação etc. Na primeira onda imigratória entre 1860-1895, os italianos do Norte-Piemonte, Lombardia, Toscana, os espanhóis do Norte-Basco e catalães, os franceses do sudoeste, os austríacos e os alemães do Sul, que chegaram, vinham com pouco dinheiro, apresentavam baixo nível de especialização (agrícola, artesanal) instrução primária e um grande desejo de ascender na escala social. $\mathrm{Na}$ segunda onda imigratória em 1895 e 1930, alemães, ingleses e franceses que entraram no país já eram mais qualificados.

5 Em 1857, foi criada a entidade operária Sociedade Tipográfica Bonarense, considerada a mais antiga do país. Em 1858, essa sociedade liderou a primeira greve importante da Argentina.

Hist. R., Goiânia, v. 19, n. 3, 2014 
Foram criadas em 1881, a Unión Obreros Panaderos, a Sociedad de Obreros Molineros, em 1882 a Unión Oficiales Yeseros, em 1883, a Sociedad Obreros Tapiceros e a Sociedad de Mayorales y Cocheros de Transvias, a Sociedad de Resistencia de Obreros Marmoleros, em 1885, a Sociedade de Obreros Panaderos e em 1887, os condutores e foguistas ferroviários organizaram La Fraternidad. Ainda que esses grêmios fossem basicamente de ajuda mútua, os três últimos já tinham uma tendência à luta social. Ver Hiroschi Matsushita (1983, p. 22).

6 Os anarquistas usaram largamente a imprensa. Desde 1860, foram publicados os primeiros jornais que tratavam da classe operária e de sua condição social. Entre 1870 e 1880, os jornais anarquistas que apareceram em grande número tiveram vida curta e distribuição limitada. Por volta de 1890, El Perseguido chegou a distribuir 4.000 cópias. Ver Emilio Corbiere (apud LITTLE, 1977 [1971], p. 36).

7 Os socialistas opuseram-se veementemente à primeira greve geral argentina e 1902, que gerou a Lei de Residência de 23 de novembro do mesmo ano.

8 Em 1902 ocorreu a chamada greve geral liderada pelos trabalhadores do Mercado Central de Frutos. O governo respondeu com o decreto de estado de sítio. Os anos de 1903 e 1904 foram marcados pelo aumento do número de greves, principalmente, depois da violência da polícia nas celebrações do primeiro de maio de 1904. A essa altura os socialistas que sempre foram contra as greves, passaram a apoiar e organizar "greves parciais" que, segundo eles, se realizadas com ordem, não provocariam reações do governo. Ainda assim a polícia não permitiu nenhum tipo de demonstração popular até o sério confronto de maio de 1909 , quando oito anarquistas foram mortos e vários outros feridos. Em novembro de 1909, enquanto os socialistas continuavam a advogar pela não-violência, foi assassinado o odiado chefe de polícia Ramón L. Falcón, "símbolo da lei e da ordem na Argentina". O Estado respondeu ao ato criminoso com o decreto do estado de sítio por 60 dias; censura de jornais; proibição de reuniões; e deportação de militantes políticos (RICHARD, 1977, p. 48-53).

9 A Lei de Residência autorizava o governo a deportar todo o estrangeiro cuja conduta "comprometesse à segurança nacional ou perturbasse a ordem pública", proibia a entrada dos culpados de delito e poderia deportar no prazo de três dias a quem fosse passível de condenação. A Lei de Residência tinha como objetivo isolar o trabalhador imigrante da sociedade argentina. A participação em greves poderia convertê-lo em um estrangeiro indesejável, agitador profissional ou elemento subversivo. A lei de Defesa Social foi promulgada em 1910, em conseqüência da greve geral de 1909 marcada pela violência e o assassinato nesse mesmo ano do chefe de polícia de Buenos Aires. Essa lei reforçou a Lei de Residência, facultando o governo deportar de imediato os dirigentes estrangeiros indesejáveis e a adotar outras medidas necessárias para preservar a ordem. A Lei Sáenz Peña é o conjunto de leis da reforma eleitoral promulgada em 1912. A partir de então foi estabelecido o sufrágio universal obrigatório para nativos maiores de 18 anos (WRIGHT \& NEKHOM, 1990).

10 Observação: Sebastián Marotta foi secretário geral do IX FORA.

11 A partir de 1915, passaram a existir dois FORA. O do IX Congresso (IX FORA) e o do V Congresso (V FORA) realizado em 26 de agosto de 1905 em Buenos Aires. Este último 
foi controlado pelos anarco-sindicalistas, fortalecidos perante os socialistas pela presença dos sindicalistas. Para reforçar suas posições e reafirmar suas posturas ideológicas negaram qualquer acordo obrigando os sindicalistas a seguirem suas posições. Isso levou a posterior ruptura interna entre sindicalistas e anarco-sindicalistas. O V Congresso do FORA passou à história do movimento operário como o Congresso do "comunismo anárquico".

12 Segundo Foucault (1999, p.200), Boulainvilliers “definia o princípio daquilo que se poderia denominar o caráter relacional do poder: o poder não é uma propriedade, não é uma potência; o poder sempre é apenas uma relação que só se pode, e só se deve estudar de acordo com termos entre os quais atua essa relação. Portanto, não se pode fazer nem a história dos reis nem a história dos povos, mas a história daquilo que constitui, um em face do outro, esses dois termos, dos quais um nunca é infinito e o outro nunca é zero".

13 A mudança do nome do Partido Socialista Internacional para Partido Comunista foi uma obediência às deliberações do II Congresso da Internacional Comunista, realizada em Moscou, em 2 de julho de 1920. A direção do Partido Socialista Internacional Argentino convocou o I Congresso Extraordinário, que se realizou nos dias 25 e 26 de dezembro de 1920, em Buenos Aires, com a finalidade de aceitar as 21 condições aprovadas pelo II Congresso da Internacional Comunista. Neste Congresso Victorio Codovilla anunciou os fundamentos sobre a necessidade de mudar o nome do Partido: "Na mesma situação de ontem, quando o nome de nosso Partido teve de agregar-se à palavra 'Internacional' para reafirmar categoricamente nosso conceito notadamente internacionalista frente ao chauvinismo nacionalista e 'patriotero' do mal chamado Partido Socialista, hoje devemos mudar o nome do Partido Internacional pelo de Partido Comunista reivindicado pelo nome do glorioso Manifesto Comunista de Marx e Engels". CODOVILLA, 1947, p.44) Tanto a mudança do nome como as 21 condições da Internacional foram aceitas por unanimidade. Ver: CODOVILLA, Victorio. Esbozo de Historia del Partido Comunista de la Argentina. 1918, 6 de Enero - 1948 (Buenos Aires, Editorial Anteo, 1947, p. 44. [Tradução do autor]

14 "Uma cultura é também um conjunto de recursos diversos, na qual o tráfico passa entre o literal e o oral, o que é superior e o subordinado, a vila e a metrópole; é uma arena de elementos conflitantes, que exige uma pressão obrigatória - como, por exemplo, nacionalismo ou ortodoxia religiosa predominante ou consciência de classe - para se constituir como 'sistema'. E, de fato, o próprio termo 'cultura', com sua confortável súplica de unanimidade, pode servir para distrair atenção das contradições sociais e culturais, das rupturas e oposições dentro do todo. Neste ponto generalizações para idéias universais de 'cultura popular' ficam vazias a não ser que sejam firmemente situadas em contextos históricos específicos” THOMPSON, 1993, p. 6-7).

15 Ver sobre o tema Molas (1968) Alsina (1910) e Godio (2000). 


\section{REFERÊNCIAS}

ALSINA, Juan A. La Immigración en el Primo Siglo de la Independencia. Buenos Aires: F.S.Alsina, 1910.

BAILY, Samuel. Movimiento obrero, nacionalismo y política en la Argentina. Buenos Aires: Paidós, 1984.

BEYHANT, Gustavo et al. O imigrante no sistema ocupacional argentino. In: DI TELLA, Torcuato et al. Argentina, sociedad de masas. Buenos Aires: Editora Universitaria de Buenos Aires, 1965.

BOGUE, Donald. Migración interna. In: LATTIS, Alfredo. Las migraciones en la Argentina entre mediados del Siglo XX: Temas de Población de la Argentina - Aspectos Demográficos. Centro Latino Americano de Demografia. Buenos Aires: 1973, Serie E, n. 13.

BOURDÉ, Guy. La classe ouvrière argentine: 1929-1964. Paris: Éditions L'Harmattan, 1987.

CAMPO, Hugo del. Sindicalismo y peronismo. Buenos Aires: Clacso, 1983.

COSTA, Victor Garcia. El obrero: selección de textos. Buenos Aires: Centro Editor de América Latina, Biblioteca Política Argentina, 1985.

COVILLA, Victorio. Esbozo de Historia del Partido Comunista de la Argentina1918 - 6 de enero - 1948. Buenos Aires: Editorial Anteo, 1947.

FOUCAULT, Michel. Em defesa da sociedade. São Paulo: Martins Fontes, 1999.

GERMANI, Gino et al. Argentina Sociedad de Massas. Buenos Aires: Editora Universitaria de Buenos Aires, 1965.

GODIO, Julio. Historia de movimiento obrero argentino. Buenos Aires: Ediciones Corregedor, 2000.

LATTES, Alfredo E. La migración como fator de cambio de la población en la Argentina. Centro de Investigaciones Sociales, Buenos Aires, Publicación del Programa Población y Sociedad, Instituto Torcuato di Tella, n. 76, 1972.

LITTLE, Walter. The popular origins of Peronism. In: ROCK, David. (Ed.) Argentina in the twentieth century. London: Gerald Duclaworth \& Co. Ltda, 1975. 
MACPHERSON, C.B. A democracia liberal. Rio de Janeiro: Zahar, 1978.

MAROTTA, Sebastián. El movimiento sindical argentino: sus génesis y desarrollo. V.II. Buenos Aires: Lacio, 1960.

MATSUSHITA, Hiroschi. Movimiento obrero Argentino 1930-1945. Buenos Aires: Siglo Veinte, 1983.

ODDONE, Jacinto. Gremialismo proletário argentino. Buenos Aires: La Vanguardia,1949.

ROCK, David. Politics in Argentina 1890-1930: the rise and fall of radicalism. Cambridge: Cambridge University Press, 1975.

RODRÍGUEZ, Ricardo Molas. Historial social del gaucho. Buenos Aires: Mam, 1968.

THOMPSON, Edward P. Customs in common. New York: The New York Press, 1993.

WRIGHT, Iones S. e NEKHOM, Lisa P. Diccionario historico argentino. Buenos Aires: Emecé, 1990. 